\section{GROUP1 and GROUP2: BASIC programs for laboratory research on the commons dilemma and group persuasion}

\author{
JUDITH CHAPMAN, LI-TZE HU, \\ and BRIAN MULLEN \\ Syracuse University, Syracuse, New York
}

The BASIC programs, GROUP1 and GROUP2, described here provide the user with computer-based methodologies for research on the commons dilemma and on group persuasion, respectively. Features common to both programs will be described first, followed by features unique to each program.

\section{Common Features}

Each program has the flexibility of being run with differing numbers of participants, and each prompts the user for the number of subjects participating and the number of experimenters present during each session. This allows for an estimation of group composition within each session and serves as a basis for comparing group compositions across sessions (for discussions of group composition effects across a variety of problem areas see Jackson, 1986; Latane, 1981; Mullen, 1983, 1986).

Each program includes instructions and scale items for the Linguistic Implications Form (Wegner \& Guiliano, 1980), a questionnaire to measure self-attention (Carver \& Scheier, 1981; Wickland, 1980). The user can substitute in this section of the program items for anxiety, selfesteem, or any other relevant mediating mechanism.

Both programs output latency measures (MacLachlan, Czepiel, \& LaBarbera, 1979) for responses to the questionnaire items and the dependent variable of interest.

\section{GROUP1: Commons Dilemma Program}

In GROUP1, the commons dilemma program, participants are required to harvest points from a common resource pool across 10 experimental trials. The size of the common resource pool is $50(N)$, where $N=$ the number of participants taking part in any one session.

Four preprogrammed practice trials allow participants to see the impact of different size harvests on the common resource pool.

Input. The participant is prompted to harvest from 0 to 9 points from the common pool on any one trial. Directions to wait for further instructions follow each harvesting decision and ensure simultaneous progression through trials when $N>1$. The prompt for each successive trial is accompanied by presentation of the participant's individual cumulative harvest to that point and the current

The authors' mailing address is: Department of Psychology, Syracuse University, Syracuse, NY 13244-2340. pool size. The current pool size reflects the participant's own harvest plus a preprogrammed harvest rate of 5 points per trial for each other participant, multiplied by a $10 \%$ replenishment rate. The preprogrammed harvest rate for other participants allows a gradual depletion of the common pool at a slow rate. The $10 \%$ replenishment rate reflects the fact that most resources replenish slowly over time. Both the harvest rate and the replenishment rate can be varied by the user to simulate more severe or more genial resource conditions.

Output. This program outputs the number of participants and experimenters present during the session, responses to the questionnaire items, latency of responses to the questionnaire items, harvest size per trial, and the latency of each harvesting response.

\section{GROUP2: Group Persuasion Program}

This program provides the user with a participant's opinion on a specified attitudinal item after exposure to opinions of others on the same item. It can be used in conjunction with previously measured attitudes toward the same target item, providing data for a pre- and postmeasurement design. Additional persuasion techniques can be implemented between portions of the program.

Input. The participant is prompted to press a key to view an opinion on a specific item, ostensibly expressed by a subject in an earlier study. The opinion is represented as an " $\mathrm{x}$ " on a 9-point scale, ranging from unfavorable to favorable. The participant is prompted to continue pressing that key for opinions of additional prior subjects, until a good idea of the "typical" opinion on that item is obtained. The opinions of these hypothetical others are preprogrammed to represent a moderately unfavorable typical opinion on the item. The distribution of the opinions of the hypothetical prior subjects can be modified by the user to simulate extreme or moderate typical opinions.

The participant is then prompted to enter his/her own opinion to the same item, on an identical 9-point scale.

Output. This program outputs the number of participants and experimenters present in each session, responses to the questionnaire items, latency of responses to the questionnaire items, the number of opinions of others sought, the total latency and mean latency of opinions sought, the participant's opinion, and the latency of the participant's opinion responses.

\section{Limitations}

A separate microcomputer is required for each participant in each session.

\section{Language}

Both programs are written in Radio Shack Level II BASIC and can be readily translated into other versions 
of BASIC. GROUP1 takes up less than 4300 bytes of memory and consists of 191 lines. GROUP2 takes up less than 5500 bytes of memory and consists of 209 lines.

\section{Availability}

Program listings are available free of charge from Brian Mullen.

\section{REFERENCES}

CARVER, C. S., \& SCHEIER, M. F. (1981). Attention and self-regulation: A control theory approach to human behavior. New York: SpringerVerlag.

Maclachlan, J., Czepiel, J., \& LaBarbera, P. (1979). Implementation of response latency measures. Journal of Marketing Research, XVI, 573-577.
JACKSON, J. M. (1986). Social impact theory. In B. Mullen \& G. R. Goethals (Eds.), Theories of group behavior. New York: SpringerVerlag.

Latane, B. (1981). The psychology of social impact. American Psychologist, 36, 343-356.

MulleN, B. (1983). Operationalizing the effect of the group on the individual: A self-attention perspective. Journal of Experimental Social Psychology, 19, 295-322.

Mullen, B. (1986). Self-attention theory. In B. Mullen \& G. R. Goethals (Eds.), Theories of group behavior. New York: SpringerVerlag.

Wegner, D. M., \& Guiliano, T. (1980). Arousal-induced attention to self. Journal of Personality \& Social Psychology, 38, 719-726.

WICKLAND, R. A. (1980). Group contact and self-focused attention. In P. B. Paulus (Ed.), Psychology of group influence. Hillsdale, NJ: Erlbaum.

(Manuscript accepted for publication September 12, 1986.) 